\title{
Stem Cells in Kidney Regeneration Following Acute Renal Injury
}

\author{
FANGMING LIN \\ Department of Pediatrics, University of Texas Southwestern Medical Center at Dallas, TX 75390
}

\begin{abstract}
Acute renal failure has 50-80\% mortality. Currently, treatment options for this life-threatening disease are limited. Stem cells offer an exciting potential for kidney regeneration. This review discusses pathogenesis of acute renal failure resulting from ischemiareperfusion injury and the role of stem cells in reversing or mitigating this disorder. Specifically, the issues of differentiation of kidney cells from embryonic stem cells and bone marrow stem cells, and whether adult kidney stem/progenitor cells exist in the postnatal kidney are discussed. Evidence to support the conclusion that intra-renal cells, including surviving tubular epithelial cells and potential renal stem/ progenitor cells, are the main source for renal regeneration is provided. Future research in selecting the type(s) of stem cells and optimizing the dose, frequency and route of administration of the cells will be fundamental in successful cell replacement therapy in acute renal failure. Methods for enhancing endogenous renal cell proliferation and differentiation for renal repair continue to be important research directions. (Pediatr Res 59: 74R-78R, 2006)
\end{abstract}

Tem cells are generally defined as clonogenic cells that are $\checkmark$ capable of both self-renewal and multi-lineage differentiation (1-3). The earliest stem cell in ontogeny is the zygote, which gives rise to the cells of the entire organism as well as placenta. As development proceeds, cells derived from the totipotent zygote are channeled to a particular pathway and the developmental potential becomes more restricted. Embryonic stem cells (ES cells) have been derived from the inner cell mass of the blastocysts of mice, nonhuman primates, and humans (4-7). ES cells are able to differentiate into cells of all three somatic cell lineages (ectoderm, mesoderm, and endoderm) and germ cells and therefore are pluripotent. They have unlimited self-renewal and differentiation potential. In the postnatal period, somatic stem cells or adult stem cells have been identified in several organs and have been shown to be able to differentiate into a limited number of cell types. For example, in the adult bone marrow there are hematopoietic stem cells (HSC) and mesenchymal stem cells (MSC). HSC produce all types of blood cells, and MSC have the ability to differentiate into cells of adipocyte, chondrocyte, or osteocyte lineages (8). Somatic stem cells are more restricted in their self-renewal and differentiation potential compared with ES cells and therefore are considered multipotent.

Received November 28, 2005; accepted January 9, 2006.

Correspondence: Fangming Lin, M.D., Ph.D., Department of Pediatrics, University of Texas Southwestern Medical Center at Dallas, 5323 Harry Hines Boulevard, Dallas, TX 75390-9063; e-mail: Fangming.lin@utsouthwestern.edu

This work was supported by National Institutes of Health grants K08 DK062839 and R01 DK66535, and grant support from the Children's Hospital and Medical Center of Dallas.

DOI: 10.1203/01.pdr.0000205156.85990.12
A growing body of evidence has shown that under certain conditions some somatic stem cells are able to cross lineage boundaries and differentiate into cells of different organs. Several excellent publications have described stem cell placticity in detail (1,9-13). For example, a single bone marrowderived stem cell differentiates into epithelial cells in the liver, lung, skin and gastrointestinal tract (11). In a mouse model of human tyrosinemia type 1 , repopulation of hepatocytes from injected HSC was reported. HSC injection rescued the mice from liver failure (12). The mechanism of hepatocyte formation from transplanted HSC was due to cell fusion of HSC with hepatocyte and not by true differentiation (14). It is believed that bone marrow stem cells do not play a significant role in replacement of epithelial cells in the liver in any known form of hepatic injury (15). We studied plasticity of bone marrow cells in forming renal cells in searching for new therapy for acute renal failure, a disease with high mortality due to limited treatment options. We derived the similar conclusion that bone marrow cells made only a minor contribution to renal regeneration after acute ischemia-reperfusion injury (16). This review will summarize some published data to address the role of bone marrow cells as well as ES cells and potential renal stem/progenitor cells in renal regeneration after acute renal ischemia-reperfusion injury.

\section{PATHOGENESIS AND CLINICAL CONSEQUENCE OF ACUTE RENAL FAILURE}

Renal ischemia-reperfusion injury is a well-established mouse model to study the pathogenesis of human acute renal failure that results from major surgery, trauma, hypothermia or sepsis. The main pathogenesis of ischemia-reperfusion injury includes acute tubular necrosis and apoptosis, glomerular injury and inflammation (17). It is characterized by renal tubular cell detachment from the basement membrane by the mechanisms of altered metabolism, inflammatory process, free radical generation and apoptosis (18). The injury results in decreased renal plasma flow and decreased glomerular filtration rate (GFR).

Ischemic injury triggers tubular regeneration. Studies in rodents showed that regeneration of tubules starts in the

Abbreviations: BrdU, bromodeoxyuridine; ES cells, embryonic stem cells; G-CSF, granulocyte colony-stimulating factor; GFP, green fluorescent protein; HGF, hepatocyte growth factor; HSC, hematopoietic stem cells; MSC, mesenchymal stem cells 
second day, and after $10 \mathrm{~d} 50 \%$ of the tubules have regenerated (19), although complete restoration of the tubular morphology may take up to $4 \mathrm{wk}(20,21)$. Blood urea nitrogen (BUN) and creatinine may return to normal level in $7-10 \mathrm{~d}$ in most animal models. However compromised GFR can persist for a longer time (22) and other long-term consequences of ischemia-reperfusion injury include urine concentrating defect and proteinuria (23).

Despite great effort in studying pathogenesis and searching for new therapies for acute renal failure, very little progress has been made in improving the outcomes of this disease. The mortality of human acute renal failure remains between 50 $80 \%(17,24)$. Currently, the only treatment options are dialysis and other supportive measures while waiting for return of renal function. Because stem cells have diverse developmental potential, they have opened a new avenue for potential effective treatment of acute renal failure. In exploring this possibility, we need to address the question of whether stem cells have the ability to reverse or mitigate the pathogenesis of ischemic injury. Specifically, if stem cells can decrease tubular cell death, attenuate glomerular injury, decrease inflammation, and accelerate renal regeneration.

\section{DIFFERENTIATION OF ES CELLS INTO RENAL CELLS}

ES cells have the potential to differentiate into all types of cells in the body. Human ES cells could be induced to differentiate in vitro into WT1- and renin-expressing cells with the treatment of several growth factors (25). When mouse ES cells were injected into the mouse embryonic kidney organ culture that mimics the microenvironment of the developing kidney, ES cell-derived tubules were observed. These tubules expressed Na-K-ATPase and renal proximal tubular cell markers (26). In general, the efficiency of renal cell differentiation in culture is low. Recently, Kim and Dressler demonstrated that when treated with retinoic acid, Activin-A and Bmp7, mouse ES cells could be induced to differentiate into cells expressing markers for intermediate mesoderm, the embryonic kidney precursor (27). Treated ES cells formed tubular structures on culture plates and gave rise to tubular epithelial cells with high efficiency when injected into mouse embryonic kidney organ cultures (28). Currently, methods of selective induction of human ES cells into renal cells for production of sufficient quantity of cells for clinical use are yet to be discovered. Furthermore, methods to isolate renal cells with high purity need to be developed because undifferentiated ES cells can form teratoma in vivo.

\section{DIFFERENTIATION OF BONE MARROW CELLS INTO RENAL CELLS}

Bone marrow stem cells have the plasticity to differentiate into cells of other organ systems. Poulsom et al reported that bone marrow-derived cells with epithelial cell markers were detected in normal mouse kidneys and in kidneys of male patients who received kidney transplant from female donors (29). Similarly, Gupta et al reported the $1 \%$ of the regenerating renal tubules contained Y-chromosome ${ }^{+}$cells in female donor kidneys that were transplanted into the male hosts (30). Differentiation of bone marrow cells to glomerular mesangial cells in a rat model of glomerular nephritis has been reported (31). Duffield et al showed the expression of endothelial markers in the peri-tubular capillary from bone marrowderived cells in mice with renal ischemic injury, suggesting the formation of endothelial cells from bone marrow cells (32).

We studied the contribution of bone marrow stem cells to renal regeneration in mouse models of kidney ischemiareperfusion injury. We purified HSC ( $\mathrm{Lin}{ }^{-} \mathrm{Scal}-1^{+}{ }^{+} \mathrm{ckit}^{+}$cells) from male transgenic Rosa26 mouse donors and injected intravenously (IV) into wild-type female mouse hosts that had renal ischemic-reperfusion injury. X-gal positive cells were detected in the host kidneys, especially in the S3 segment of the proximal tubules where most injury and regeneration occurred. Immunostaining with antibodies to $\beta$-galactosidase and proximal tubular cell markers further supported the formation of proximal tubular epithelial cells from transplanted HSC. Furthermore, donor Y-chromosome ${ }^{+}$cells were detected in the kidneys of female hosts (33).

To identify $\mathrm{Y}$-chromosome ${ }^{+}$cells in the post-ischemic kidneys, we combined Y-chromosome fluorescent in situ hybridization (FISH) analysis with immunostaining of markers for kidney tubular epithelial, glomerular, and interstitial cells (16). We showed that injected whole bone marrow cells gave rise to many types of renal cells. Y-chromosome ${ }^{+}$cells express specific proximal tubular and collecting duct cell markers (Fig. 1A,B). Male-derived cells localized to the tubules and proliferated as evidenced by the incorporation of thymidine analogue, bromodeoxyuridine (BrdU, Fig. 1C). These results indicate the repopulation of renal tubular epithelial cells by bone marrow-derived cells. Similarly, a small number of bone marrow-derived endothelial cells, mesangial cells and podocytes were detected in the glomeruli. Interestingly, most Ychromosome $^{+}$cells were localized to the interstitium and some of them expressing $\alpha$-smooth muscle actin, indicating the formation of myofibroblasts. Of all the male bone marrowderived cells in the female kidney, $8.4 \%$ are tubular epithelial

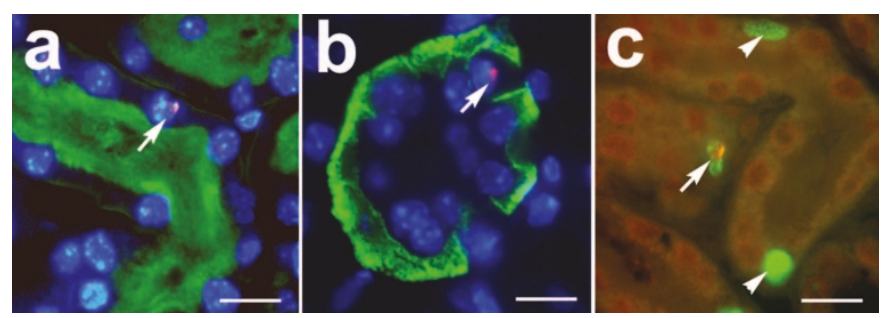

Figure 1. Bone marrow-derived renal tubular epithelial cells. Male bone marrow cells were injected into female mice with renal ischemia-reperfusion injury and Y-chromosome FISH analysis (red signals) combines with immunostaining for tubular markers or BrdU (green signals) showed the presence of Y-chromosome ${ }^{+}$proximal tubular cells stained with Lotus tetragonolobus agglutinin ( $a$, arrow) or collecting duct principal cells stained with antibody to aquaporin 3 water channel AQP3 ( $b$, arrow). The basolateral staining of AQP3 clearly defines the intra-tubular localization of $\mathrm{Y}$-chromosome ${ }^{+}$cells. Y-chromosome ${ }^{+}$cells in the tubules proliferated as indicated by the incorporation of BrdU ( $c$, arrow). Arrow heads indicate tubular cell proliferation from host origin. Nuclei were counter-stained with DAPI (blue) in panels $a$ and $b$. Scale bar, $20 \mu \mathrm{m}$. 
cell, $10.6 \%$ are glomerular cells, and $81 \%$ are interstitial cells. The presence of $\mathrm{Y}$-chromosome in the tubules and in the glomeruli was confirmed using an image de-convolution technique to exclude the possibility of overlay of Y-chromosome signals from interstitial cells. More collagen deposition was noted in the interstitium of mice given bone marrow cell injection. The abundant bone marrow-derived cells in the interstitial may contribute to renal fibrosis in the injured kidney, which can be a clinical concern.

The effect of mobilization of bone marrow stem cells on renal recovery has been investigated (32,34-36). Controversies exist as to whether there is a measurable degree of bone marrow cell mobilization into the circulation after renal ischemic injury $(32,34)$. Kale et al reported increased number of circulating Lin $^{-}$Sca- $1^{+}$cells $24 \mathrm{~h}$ after injury, whereas Duffield $e t$ al failed to detect any bone marrow mobilization. The mechanism of bone marrow cell mobilization following acute renal injury is not understood. Increased levels of granulocyte colony-stimulating factor (G-CSF) in the circulation and in the kidney have been shown after renal ischemia-reperfusion injury (37). Togel et al demonstrate up-regulation of renal expression of stromal cell-derived factor-1 (SDF-1) which interacts with its receptor CXCR4 on the bone marrow cells to induce mobilization and homing of stem cells into the kidney for renal protection (36). However, the same group also shows that forced bone marrow mobilization with exogenous administration of G-CSF worsens acute renal failure, presumably by enhanced kidney inflammation that is related to granulocytosis (35).

\section{RENOPROTECTION OF MESENCHYMAL STEM CELLS BY DECREASING INFLAMMATION AND ENHANCING RENAL REGENERATION}

There are several reports about renoprotective effect of mesenchymal stem cells in rodent models of ischemia- or chemical-induced acute renal failure. Morigi et al injected MSC isolated from male mice into the veins of female mice that had renal injury induced by cisplatin and observed formation of male cell-derived tubular epithelial cells. Mice received MSC had accelerated tubular regeneration and improved renal function. In contrast, injection of the same number of HSC $\left(\mathrm{Lin}^{-} \mathrm{ckit}^{+}\right.$cells) did not have a beneficial effect. The mechanism of renal protection by MSC is thought to be due to differentiation of MSC into renal tubular epithelial cells, although the extent of MSC differentiation was not evaluated in this study (38). In another study conducted by Togel $e t a l$, rat kidneys were injured by ischemia and the rats were injected with MSC into the carotid artery. A similar protective effect was observed in improvement of renal morphology and renal function. However, MSC-derived renal cells were not detected. Instead, an altered expression pattern of inflammatory mediators favoring anti-inflammatory processing was noted in the kidney. The authors concluded that the protective effect of MSC was mediated by complex paracrine mechanisms that promote kidney recovery rather than direct differentiation (39). Renoprotective factors produced by MSC have not been clearly identified. Cultured human MSC express hepatocyte growth factor (HGF) and its receptor c-met at both mRNA and protein levels (40). Since HGF has been shown to enhance renal regeneration after injury in mice (41), HGF could be one of the MSC-derived renoprotective molecules that plays a role in accelerating kidney recovery. Although this hypothesis needs to be tested, the expression of growth factor and growth factor receptor by human MSC certainly offers a potential of using human MSC to enhance renal regeneration.

\section{INTRA-RENAL CELLS AS THE MAIN SOURCE FOR RENAL REGENERATION}

Renal recovery after ischemic injury requires cell proliferation to reconstruct damaged tubular structure. Because large numbers of mitotic cells with the expression of mesenchymal marker vimentin and renal developmental gene Pax2 were observed in the tubules of the injured area in the first 24 to $48 \mathrm{~h}$ after injury, dedifferentiation and proliferation of surviving epithelial cells have long been regarded as the mechanism of renal repair (42). We and others have shown that bone marrow-derived cells can integrate into the renal structure during the repair process. To evaluate the differential contribution of extra-renal cells and intra-renal cells to renal repair, we used genetic marking to label mature tubular epithelial cells originated from intra-renal source with green fluorescent protein (GFP) and counted BrdU incorporation in GFPexpressing cells (intra-renal source) and in Y-chromosome ${ }^{+}$ cells (extra-renal source given by IV injection at $2 \mathrm{~h}$ after renal injury) in the post-ischemic female kidneys. The results show that at $28 \mathrm{~d}$ after injury, the majority (89\%) of the regenerating cells are descendents of either surviving tubular epithelial cells or potential renal stem cells, both of which are derived from intra-renal source. In contrast, bone marrow cells made only a minor contribution to tubular structural repair. Moreover, GFP-positive mature epithelial cells expressed vimentin, which provided direct evidence to support the conventional wisdom of dedifferentiation of surviving epithelial cells for tubular repair after acute injury.

Duffield et al created mice with chimeric bone marrow between wild-type and Rosa26 or GFP mice and performed renal ischemic injury. A large number of bone marrowderived cells were observed in the interstitium but not in the renal tubules at 2,7 or $21 \mathrm{~d}$ after the injury. Similarly, in female mice with male bone marrow chimerism, no Ychromosome $^{+}$cells were detected in the tubules at 7 or $15 \mathrm{~d}$ after the injury. The authors concluded that restoration of renal tubules was due to self-repair from epithelial cells (32). This study further strengthens the importance of intra-renal cells in kidney regeneration. The difference of the small contribution of bone marrow cells to forming tubular cells in mice injected with bone marrow cells after injury and the inability of bone marrow cells to form tubular cells in mice with chimeric bone marrow could be explained by the fact that there is limited mobilization of bone marrow stem cells into the circulation to reach the sites of injured kidneys (32). In contrast, injection of bone marrow cells into the circulation provides direct access of stem cells into the kidney. It is interesting to note that the 
number of bone marrow-derived cells in the tubular, glomerular and interstitial compartments of the kidney increases with time (16). After IV injection of bone marrow cells, the earliest time point that we could detect any Y-chromosome ${ }^{+}$cells in the renal tubules was $5 \mathrm{~d}$ post injury. At $28 \mathrm{~d}, 0.67 \%$ of the tubular cells in the injured kidneys contained Y-chromosome. The mechanism and significance of increasing number of bone marrow-derived cells in the kidney is not understood at the present time.

The ultimate goal of studying bone marrow contribution to renal regeneration is to develop potential treatment for acute renal failure with bone marrow-derived cells. Kale et al injected one dose of $2.9 \times 10^{5} \mathrm{Lin}^{-}$cells into mice with renal ischemic injury and observed significant improvement of BUN. In our study, a single injection of $1 \times 10^{6}$ whole bone marrow cells into the systemic circulation after renal injury did not improve renal function in mice, which is in agreement with the minor contribution to tubular structural recovery (16). It is also possible that mature white blood cells in the whole bone marrow may elicit exaggerated inflammation in the ischemic kidney and therefore compromise the protective effect of bone marrow stem cells. It is estimated that in $1 \times$ $10^{6}$ of freshly isolated whole bone marrow cells there are very few numbers of mesenchymal stem cells that have been reported to protect renal function $(32,38,39)$. Interestingly, injection of fibroblasts offered the same functional protection (32). More studies need to be performed to determine the optimal type(s) of bone marrow cells, the number of cells per treatment, and the frequency and route of injection for cell replacement therapy.

\section{RENAL STEM/PROGENITOR CELLS IN POSTNATAL KIDNEYS}

The facts that postnatal kidney undergoes slow but constant turnover, and the kidney can regenerate after injury suggest that postnatal kidney contains a population of self-replicating cells. At the present time, a single cell that fits into the criteria of stem cells (self-renewal and multi-lineage differentiation) has not been isolated from the kidney. Because stem cells can self-renew and do not divide frequently, they will incorporate BrdU during self-renewal and retain BrdU. BrdU label retaining cells have been shown to have stem cell properties in the organs with fast turnover, such as in the skin and intestinal tract. Using a similar method, Oliver et al injected newborn mice and rats with $\mathrm{BrdU}$ and let cells with relatively fast cycling dilute BrdU for over 2 mo. BrdU retaining cells were identified in the interstitial and tubular compartments of the renal papilla after 2-10 mo of chase. Their number decreased after ischemic injury, possibly by migration into injured area for renal repair. Staining with proliferation marker Ki67 proved the proliferative capacity of the cells. When dispersed cells from renal papilla were placed in culture, they expressed neuronal or epithelial cell makers (43). These results suggest that BrdU retaining cells in the papilla can proliferate and participate in renal repair. It is currently unknown whether these cells are undifferentiated (like stem cells) and what their complete developmental potential is. Studies by Vogetseder $e t$ al demonstrate that after 8-35 wk of BrdU injection given in the neonatal period, BrdU retaining cells in the rat renal tubules possess features of differentiated epithelial cells with the expression of Na-K-ATPase and sodium/phosphate cotransporter (44). Self-duplication of preexisting pancreatic $\beta$-cells has been reported as the mechanism of new $\beta$-cell formation in adult life and after pancreatectomy in mice (45). Like the pancreas that has relatively slow turnover, it is possible that in the kidney preexisting tubular epithelial cell can maintain kidney structure under normal condition and regenerate the kidney following injury. It is our effort to develop methods to selectively label preexisting renal epithelial cells to allow us to track the fate of these cells to prove this possibility.

\section{POTENTIALS OF STEM CELLS FOR TREATMENT OF ACUTE RENAL FAILURE}

Postnatal kidneys have the capacity to regenerate following ischemic or chemical injury to renal tubular epithelial cells. The source of the regenerating cells includes surviving epithelial cells, putative renal stem cells, and bone marrow stem cells (46-48) Figure 2 illustrates the contributions of these cells to renal repair. To develop stem cells as potential therapeutic agents for acute renal failure, more research needs to be conducted to have more in-depth understanding of renal injury and repair. ES cells have unlimited developmental potential and could be induced to differentiate into tubular structure and express renal cell markers, they could offer a large source for cell replacement therapy. Before clinical use, we need to control precise renal lineage differentiation in a reproducible manner and develop methods to isolate renal cells with high purity to avoid contamination of undifferentiated ES cells that can form teratoma. Until autologous ES cells are cloned for an individual patient, immune response remains an issue. The existence of renal stem cells that meet the gold

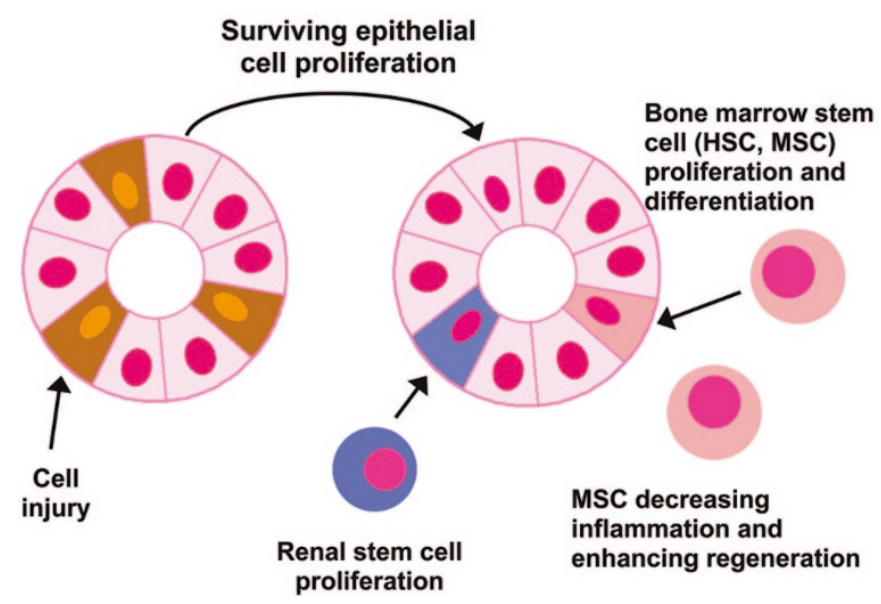

Figure 2. Source of regenerating cells for renal repair. Following acute ischemic or chemical injury, surviving tubular epithelial cells and putative renal stem cells proliferate and different into tubular epithelial cells for structural and functional repair. Bone marrow stem cells, including hematopoietic stem cells (HSC) and mesenchymal stem cells (MSC) can also participate in the repair processing by proliferation and differentiation into renal lineages. MSC have been shown to decrease inflammation and enhance renal regeneration. 
standard of self-renewal and multi-lineage differentiation needs to be proven. In the adult kidney, there are at least twenty-six types of differentiated cells. It is likely that there is no such single stem cell that can form all these cells. Despite this, we should not be discouraged. If our research effort leads to successful isolation and expansion of progenitors of tubular epithelial cells, it will be an important achievement in our attempt to replace and regenerate tubular epithelial cells that are injured or lost due to kidney diseases. Methods such as using growth factors and pharmacological agents to stimulate endogenous renal epithelial cell proliferation and differentiation may also enhance renal regeneration. Because bone marrow stem cells are readily accessible, they remain an important source for autologous cell replacement therapy. More research needs to be conducted to determine the type of bone marrow cells, dose and route of administration of the cells. For example mesenchymal stem cells have been shown to function as nursemaid to aid tissue recovery and it will be an interesting direction for further research. Currently, most renal stem cell research is focused on models of acute renal injury. The potential of stem cell therapy in chronic renal disease will be another exciting area of future research.

Acknowledgments. The author thanks Dr. Peter Igarashi for helpful suggestions and Laurel Johnson for critical reading of the manuscript.

\section{REFERENCES}

1. Weissman IL 2000 Stem cells: units of development, units of regeneration, and units in evolution. Cell 100:157-168

2. Metcalf D 2001 Hematopoietic stem cells: old and new. Biomed Pharmacother 55:75-78

3. McCulloch EA, Till JE 2005 Perspectives on the properties of stem cells. Nat Med $11: 1026-1028$

4. Martin GR 1981 Isolation of a pluripotent cell line from early mouse embryos cultured in medium conditioned by teratocarcinoma stem cells. Proc Natl Acad Sci U S A 78:7634-7638

5. Evans MJ, Kaufman MH 1981 Establishment in culture of pluripotential cells from mouse embryos. Nature 292:154-156

6. Thomson JA, Kalishman J, Golos TG, Durning M, Harris CP, Becker RA, Hearn JP 1995 Isolation of a primate embryonic stem cell line. Proc Natl Acad Sci U S A 92:7844-7848

7. Thomson JA, Itskovitz-Eldor J, Shapiro SS, Waknitz MA, Swiergiel JJ, Marshall VS, Jones JM 1998 Embryonic stem cell lines derived from human blastocysts. Science 282:1145-1147

8. Pittenger MF, Mackay AM, Beck SC, Jaiswal RK, Douglas R, Mosca JD, Moorman MA, Simonetti DW, Craig S, Marshak DR 1999 Multi-lineage potential of adult human mesenchymal stem cells. Science 284:143-147

9. Clarke DL, Johansson CB, Wilbertz J, Veress B, Nilsson E, Karlstrom H, Lendahl U, Frisen J 2000 Generalized potential of adult neural stem cells. Science 288:16601663

10. Herzog EL, Chai L, Krause DS 2003 Plasticity of marrow-derived stem cells. Blood 102:3483-3493

11. Krause DS, Theise ND, Collector MI, Henegariu O, Hwang S, Gardner R, Neutzel S, Sharkis SJ 2001 Multi-organ, multi-lineage engraftment by a single bone marrowderived stem cell. Cell 105:369-377

12. Lagasse E, Connors H, Al-Dhalimy M, Reitsma M, Dohse M, Osborne L, Wang X, Finegold M, Weissman IL, Grompe M 2000 Purified hematopoietic stem cells can differentiate into hepatocytes in vivo. Nat Med 6:1229-1234

13. Orlic D, Kajstura J, Chimenti S, Jakoniuk I, Anderson SM, Li B, Pickel J, McKay R, Nadal-Ginard B, Bodine DM, Leri A, Anversa P 2001 Bone marrow cells regenerate infarcted myocardium. Nature 410:701-705

14. Wang X, Willenbring H, Akkari Y, Torimaru Y, Foster M, Al-Dhalimy M, Lagasse E, Finegold M, Olson S, Grompe M 2003 Cell fusion is the principal source of bone-marrow-derived hepatocytes. Nature 422:897-901

15. Grompe M 2005 Bone marrow-derived hepatocytes. Novartis Found Symp 265:2027; discussion 28- 34:92-97

16. Lin F, Moran A, Igarashi P 2005 Intra-renal cells, not bone marrow-derived cells, are the major source for regeneration in post-ischemic kidney. J Clin Invest 115:17561764

17. Schrier RW, Wang W, Poole B, Mitra A 2004 Acute renal failure: definitions, diagnosis, pathogenesis, and therapy. J Clin Invest 114:5-14
18. Bonventre JV 1993 Mechanisms of ischemic acute renal failure. Kidney Int 43:1160-1178

19. Ysebaert DK, De Greef KE, Vercauteren SR, Ghielli M, Verpooten GA, Eyskens EJ, De Broe ME 2000 Identification and kinetics of leukocytes after severe ischaemia/ reperfusion renal injury. Nephrol Dial Transplant 15:1562-1574

20. Humes HD, Lake EW, Liu S 1995 Renal tubule cell repair following acute renal injury. Miner Electrolyte Metab 21:353-365

21. Witzgall R, Brown D, Schwarz C, Bonventre JV 1994 Localization of proliferating cell nuclear antigen, vimentin, c-Fos, and clusterin in the post-ischemic kidney. Evidence for a heterogenous genetic response among nephron segments, and a large pool of mitotically active and dedifferentiated cells. J Clin Invest 93:2175-2188

22. O'Donnell MP, Burne M, Daniels F, Rabb H 2002 Utility and limitations of serum creatinine as a measure of renal function in experimental renal ischemia-reperfusion injury. Transplantation 73:1841-1844

23. Basile DP, Donohoe D, Roethe K, Osborn JL 2001 Renal ischemic injury results in permanent damage to peritubular capillaries and influences long-term function. Am J Physiol Renal Physiol 281:F887-F899

24. Liano F, Pascual J 1998 Outcomes in acute renal failure. Semin Nephrol 18:541-550

25. Schuldiner M, Yanuka O, Itskovitz-Eldor J, Melton DA, Benvenisty N 2000 Effects of eight growth factors on the differentiation of cells derived from human embryonic stem cells. Proc Natl Acad Sci U S A 97:11307-11312

26. Steenhard BM, Isom KS, Cazcarro P, Dunmore JH, Godwin AR, St John PL, Abrahamson DR 2005 Integration of embryonic stem cells in metanephric kidney organ culture. J Am Soc Nephrol 16:1623-1631

27. Saxen L 1987 Organogenesis of the kidney. Cambridge University Press, Cambridge

28. Kim D, Dressler GR 2005 Nephrogenic factors promote differentiation of mouse embryonic stem cells into renal epithelia. J Am Soc Nephrol 16:3527-3534

29. Poulsom R, Forbes SJ, Hodivala-Dilke K, Ryan E, Wyles S, Navaratnarasah S, Jeffery R, Hunt T, Alison M, Cook T, Pusey C, Wright NA 2001 Bone marrow contributes to renal parenchymal turnover and regeneration. J Pathol 195:229-235

30. Gupta S, Verfaillie C, Chmielewski D, Kim Y, Rosenberg ME 2002 A role for extra-renal cells in the regeneration following acute renal failure. Kidney Int 62:1285-1290

31. Ito T, Suzuki A, Imai E, Okabe M, Hori M 2001 Bone marrow is a reservoir of repopulating mesangial cells during glomerular remodeling. J Am Soc Nephrol 12:2625-2635

32. Duffield JS, Park KM, Hsiao LL, Kelley VR, Scadden DT, Ichimura T, Bonventre JV 2005 Restoration of tubular epithelial cells during repair of the post-ischemic kidney occurs independently of bone marrow-derived stem cells. J Clin Invest 115:1743-1755

33. Lin F, Cordes K, Li L, Hood L, Couser WG, Shankland SJ, Igarashi P 2003 Hematopoietic stem cells contribute to the regeneration of renal tubules after renal ischemia-reperfusion injury in mice. J Am Soc Nephrol 14:1188-1199

34. Kale S, Karihaloo A, Clark PR, Kashgarian M, Krause DS, Cantley LG 2003 Bone marrow stem cells contribute to repair of the ischemically injured renal tubule. J Clin Invest 112:42-49

35. Togel F, Isaac J, Westenfelder C 2004 Hematopoietic stem cell mobilizationassociated granulocytosis severely worsens acute renal failure. J Am Soc Nephrol $15: 1261-1267$

36. Togel F, Isaac J, Hu Z, Weiss K, Westenfelder C 2005 Renal SDF-1 signals mobilization and homing of CXCR4-positive cells to the kidney after ischemic injury. Kidney Int 67:1772-1784

37. Zhang Y, Woodward VK, Shelton JM, Richardson JA, Zhou XJ, Link D, Kielar ML, Jeyarajah DR, Lu CY 2004 Ischemia-reperfusion induces G-CSF gene expression by renal medullary thick ascending limb cells in vivo and in vitro. Am J Physiol Renal Physiol 286:F1193-F1201

38. Morigi M, Imberti B, Zoja C, Corna D, Tomasoni S, Abbate M, Rottoli D, Angioletti S, Benigni A, Perico N, Alison M, Remuzzi G 2004 Mesenchymal stem cells are renotropic, helping to repair the kidney and improve function in acute renal failure. J Am Soc Nephrol 15:1794-1804

39. Togel F, Hu Z, Weiss K, Isaac J, Lange C, Westenfelder C 2005 Administered mesenchymal stem cells protect against ischemic acute renal failure through differentiation-independent mechanisms. Am J Physiol Renal Physiol 289:F31-F42

40. Neuss S, Becher E, Woltje M, Tietze L, Jahnen-Dechent W 2004 Functional expression of HGF and HGF receptor/c-met in adult human mesenchymal stem cells suggests a role in cell mobilization, tissue repair, and wound healing. Stem Cells 22:405-414

41. Liu Y 2002 Hepatocyte growth factor and the kidney. Curr Opin Nephrol Hypertens $11: 23-30$

42. Bonventre JV 2003 Dedifferentiation and proliferation of surviving epithelial cells in acute renal failure. J Am Soc Nephrol 14 Suppl 1:S55-S61

43. Oliver JA, Maarouf O, Cheema FH, Martens TP, Al-Awqati Q 2004 The renal papilla is a niche for adult kidney stem cells. J Clin Invest 114:795-804

44. Vogetseder A, Karadeniz A, Kaissling B, Le Hir M 2005 Tubular cell proliferation in the healthy rat kidney. Histochem Cell Biol 124:97-104

45. Dor Y, Brown J, Martinez OI, Melton DA 2004 Adult pancreatic beta-cells are formed by self-duplication rather than stem-cell differentiation. Nature 429:41-46

46. Duffield JS, Bonventre JV 2005 Kidney tubular epithelium is restored without replacement with bone marrow-derived cells during repair after ischemic injury. Kidney Int 68:1956-1961

47. Krause D, Cantley LG 2005 Bone marrow plasticity revisited: protection or differentiation in the kidney tubule? J Clin Invest 115:1705-1708

48. Haller H, de Groot K, Bahlmann F, Elger M, Fliser D 2005 Stem cells and progenitor cells in renal disease. Kidney Int 68:1932-1936 